\title{
Efeitos dos planos diretores na cobertura infraestrutural urbana: o Estado de São Paulo como estudo de caso
}

\author{
Effects of master plans on infrastructure coverage: São Paulo State as a \\ case of study
}

Tiago Augusto da Cunha[a] [D, Teresa Cristina de Almeida Faria[a] Ana Carolina Campana Nascimento[a]

[a] Universidade Federal de Viçosa (UFV), Departamento de Arquitetura e Urbanismo, Viçosa, MG, Brasil

Como citar: Cunha, T. A., Faria, T. C. A., \& Nascimento, A. C. C. (2019). Efeitos dos planos diretores na cobertura infraestrutural urbana: o Estado de São Paulo como estudo de caso. urbe. Revista Brasileira de Gestão Urbana, 11, e20180092. https://doi.org/10.1590/2175-3369.011.e20180092

\section{Resumo}

A Lei Federal n. 10.257/2001, por meio do segundo artigo, preconiza o direito às cidades sustentáveis através, por exemplo, do direito à terra urbana, à moradia, ao saneamento ambiental e, não menos importante, à infraestrutura urbana. Nesse sentido, interessa ao presente artigo investigar a associação entre Planos Diretores e infraestrutura urbana. Almeja-se compreender, ainda que resumidamente, os efeitos de políticas de planejamento local na qualidade de infraestrutura urbana. Para tanto são manejados e analisados os dados oriundos da pesquisa Perfil dos Municípios Brasileiros (MUNIC) entre 2004 e 2013. As análises são complementadas com as Informações dos Municípios Paulistas (IMP), da Fundação Sistema Estadual de Análise de Dados (SEADE) do Estado de São Paulo. Tais dados possibilitam a construção de um indicador sintético que abranje diferentes domínios: água, esgoto, resíduos sólidos, energia etc. Por fim, optou-se por realizar as análises estatísticas por meio do software $\mathrm{R}$, correlacionando ambas as variáveis através do coeficiente ponto-bisserial.

Palavras-chave: Planos Diretores. Infraestrutura. Correlação. Planejamento urbano. São Paulo.

\section{Abstract}

Federal Law 10.257/2001 - in its second article - advocates the right to sustainable cities through, for example, the right to urban land, housing, environmental sanitation and, not least, urban infrastructure. Therefore, this article aims to investigate the correlation between master plans and urban infrastructure. The aim was to understand, albeit briefly, the effects of local planning policies on the quality of urban infrastructure. In order to achieve this we have processed and analyzed the data from the survey "Profile of Brazilian Municipalities" (MUNIC) between 2004 and 2013. The analyzes are supplemented with information from Municipalities of the state of Sao Paulo (IMP), from the State System Foundation for Data Analysis (SEADE) in Sao Paulo. The available data allowed us to quickly create a synthetic indicator that cover different areas: water, sewage, solid waste, energy, etc. Finally yet

TAC é doutor em Demografia, professor, e-mail: tiagoac@ufv.br

TCAF é doutora em Planejamento Urbano e Regional, professora, e-mail: teresa.faria@ufv.br

ACCN é doutora em Economia Aplicada, professora, e-mail: ana.campana@ufv.br 
importantly, we have decided to perform the statistical analysis using the $R$ software, correlating both variables through the point-biserial coefficient.

Keywords: Master Plans. Infrastructure. Correlation. Urban planning. São Paulo.

\section{Disritmias entre esferas de planejamento, falência das políticas infraestruturais abrangentes e suas implicações territoriais}

A questão da inclusão social está no bojo da discussão do direito à cidade, mormente em uma sociedade desigual e grandemente urbanizada como é o caso da brasileira (Kowarick, 1980; Penna \& Ferreira, 2014; Maricato, 2003, 2009). Há que se ter em mente que o processo de urbanização-industrialização nacional foi uma "máquina" de segregação e exclusão social (Brandão, 2007). Neste cenário, serviços de infraestrutura estiveram aquém das reais demandas, colaborando para desigualdades socioterritoriais nas mais diferentes escalas.

Antevendo a eminência que a questão urbana tomaria nas décadas por vir, a aprovação da Constituição Federal de 1988 com a inédita inclusão de dois artigos sobre a política urbana foi uma resposta às defasagens e aos déficits gerados anteriormente (Brasil, 1988).

Mais que isto, a nova Constituição garantiu aos municípios brasileiros a atribuição de desenvolver e implementar sua política urbana, tendo como principal instrumento o Plano Diretor Participativo, descentralizando a gestão territorial às menores unidades administrativas da Federação (Oliveira, 2013).

Contudo, a real implementação da política urbana, definida nos art. 182 e 183, só foi viabilizada muito posteriormente, com a aprovação da Lei Federal n. 10.257, de 2001, conhecida como Estatuto da Cidade (Brasil, 2001), que além do Plano Diretor indica uma série de instrumentos que podem garantir seu princípio básico, qual seja: a gestão democrática e a função social da cidade e da propriedade.

Isto significa que os instrumentos contidos na referida lei têm como objetivo a promoção do direito à cidade, alcançada somente através da diminuição das desigualdades - garantida pela equidade urbana, através da justa distribuição das benesses da urbanização (Correa \& Rozas, 2006, p. 46) -, inclusive as infraestruturais.

La segunda forma de entender el desarrollo urbano es en el sentido de la creación de condiciones que hacen posible una mayor equidad en la distribución de los frutos del crecimiento y del desarrollo, de modo que disminuya progresivamente aquel segmento de la población urbana que no puede satisfacer satisfactoriamente las necesidades básicas vinculadas a la educación, la salud, el transporte, la vivienda y los servicios de saneamiento.

Em síntese, é indiscutível que o Estatuto das Cidades se trata de um grande avanço na gestão do território, uma vez que obriga planejadores e população a refletirem de maneira profunda e coordenada sobre seus problemas, meios de saná-los e objetivos futuros (Lacerda et al., 2011; Cymbalista \& Santoro, 2009).

Embora seja preciso lembrar que a transmissão da responsabilidade e, logo, paulatina autonomia dos municípios na gestão de seu próprio território conduziram, em outros tantos casos a, como bem lembra Brandão (2007), "paroquialismos". O planejamento se dobrou a interesses e urgências cotidianas e bairristas, lhes sendo subserviente. A norma foi de tal modo flexibilizada que seu fruto mais imediato foi deterioração do ambiente e da infraestrutura urbana ${ }^{1}$, fosse pelo sucateamento dos componentes já instalados ou por se furtar em promover - direta ou indiretamente - novas redes e serviços para uma demanda crescente e cambiante (Villaça, 2005; Braga, 1995). Desse modo, não são poucos os casos em que planos se omitem em cobrar elites fundiárias locais, concessionárias de prestação de serviços privadas e demais agentes públicos e/ou privados de promoção urbana das mais

\footnotetext{
1 Áreas de Proteção Permanente cada vez mais exíguas: redefinição de margens a serem protegidas, ocupações em topos de morro, em encostas com inclinações superiores a 30\% são alguns exemplos.
} 
diferentes escalas (estaduais e federais) quanto a suas reponsabilidades na ampliação de infraestruturas qualificadas (Bernardy, 2013).

Ademais, a partir de uma perspectiva histórica, a descentralização e, logo, o empoderamento municipal caminharam conjuntamente com a progressiva substituição de uma visão desenvolvimentista do Estado por outra, mais flexível ou neoliberal (Arretche, 1999). Atualmente, grassa a férrea convicção de que a intervenção estatal, por meio do ato de planejar, é inibidora, coercitiva e constrangedora de ambientes e de iniciativas que emergiriam espontanea e organicamente do Mercado. A sinergia advinda do Mercado equalizaria naturalmente as diferenças socioterritoriais estruturais. Não é fortuita, portanto, a erosão das esferas de planejamento regional e, consequentemente, dos investimentos articulados setorialmente e regionalmente em infraestrutura (Figueroa, 2004).

No entanto, os desequilíbrios de Mercado foram se acumulando dada a supressão de qualquer política pública infraestrutural nacional ou regional niveladora e a incapacidade de os municípios solucionarem problemas externos aos seus limites, mormente buscando soluções conjuntas.

Nesse sentido, as diferenças socioespaciais do Estado não foram necessariamente abrandadas, senão o intervalo entre regiões abastadas e carentes se manteve, em geral, igual, ainda que a precariedade das regiões economicamente mais carentes tenha diminuído (Santos et al., 2017). Com efeito, nos esforçaremos em ser cuidadosos nas análises ao não descuidarmos das causas estruturais que reproduzem essas desigualdades socioterritoriais. Em outras palavras, nos parece importante lembrar que a concentração espacial de atividades, dos meios de produção, da população (força de trabalho e mercado consumidor), das matérias-primas etc. não são uniformemente distribuídos no espaço, assim como as causas que conduziram a essas manifestações espaciais assimétricas também não o são (Caiado, 1995). Desse modo, não podemos imputar exclusivamente a existência ou inexistência de Planos Diretores às diferenças infraestruturais entre regiões, apesar disso, acreditamos que, ao menos em alguma medida, ele é um componente fundamental para entendê-las (Braga, 1993). Futuramente almejamos arquitetar modelos mais complexos (multifatoriais, por exemplo), afim de compreender as impedâncias na ampliação das redes infraestruturais.

No entanto, e quando este Plano Diretor inexiste? Quais são seus significados? Partimos aqui do pressuposto que, da mesma forma, sua inexistência está cheia de sentidos e de reflexos territoriais (Fausto \& Rábago, 2014; Urbano, 2005).

0 hiato criado pela ausência de uma política de planejamento territorial efetivamente abrangente desdobrou-se em igual escassez de políticas infraestruturais de amplo escopo e, por fim, na falta de propósitos indutores de equidade socioeconômica por meio da oferta de serviços mínimos a todos (Barton et al., 2007).

Partindo da acepção de vulnerabilidade social, a inexistência de agendas que induzissem a equalização de desigualdades regionais basilares por meio do desenvolvimento de infraestruturas reiterou a cisão entre territórios e classes.

Definida como um risco social, a vulnerabilidade caracteriza-se pela concentração da precariedade (ou falta) de serviços coletivos e de investimentos públicos em infraestruturas (os ativos e as estruturas de oportunidades), que desse modo provocam a desproteção social das comunidades mais carentes (Penna \& Ferreira, 2014, p. 2).

Em resumo, presumimos que a inexistência e a desarticulação entre Planos Diretores (quando estes existem) podem significar piores indicadores de infraestrutura. Em outras palavras, partimos do pressuposto de que a ausência de Planos Diretores, ainda que indireta ou tangencialmente, repercutirá nos índices de cobertura infraestrutural (Boscá et al., 2011). Vale lembrar que não nos debruçaremos sobre a qualidade da infraestrutura em si, perante a abrangência e a desagregação do recorte territorial proposto (o universo do Estado de São Paulo: 645 municípios). Decerto, a investigação dos efeitos dos Planos Diretores na qualidade infraestrutural seria interessante, senão urgente, porém a trataremos como o próximo passo da presente pesquisa, dado o banco de dados e as técnicas necessárias para tanto. Assim, inferimos que o Plano Diretor é mais uma ferramenta no cabedal daquelas voltadas ao 
ordenamento territorial (a Lei Federal n. 6.766, de 1979, é outro exemplo), contribuindo em alguma medida para controlar, por exemplo, as assincronias de velocidade e de intensidade entre processo de expansão urbana e ampliação de serviços (água, luz, esgoto e lixo) destinados à população e a seus domicílios particulares permanentes. Nesse sentido, acreditamos que pelo simples fato de controlarem melhor os perímetros urbanos e outras faces da urbanização alguns municípios possuem melhores coberturas infraestruturais do que outros. Em outras palavras, por diretrizarem a concentração espacial da população, ou, ainda, a concentração espacial das atividades urbanas, alguns municípios otimizam seus índices de cobertura infraestrutural, sem necessariamente ampliá-la (Ojima \& Hogan, 2009). Por outro lado, conjecturamos que aqueles municípios deficitários em políticas de ordenamento territorial talvez se vejam forçados a gastar mais de seus exíguos recursos para atingir níveis de cobertura infraestrutural semelhantes aos dos municípios com Planos Diretores dado o espraiamento de sua mancha urbana, fato que os leva a apresentar piores indicadores infraestruturais.

Ainda versando sobre os efeitos dos Planos Diretores nos índices de cobertura infraestrutural poderíamos refletir acerca das consequências da criação de Zonas Especiais de Interesse Social (ZEIS). Decerto há uma pluralidade de Planos Diretores, sendo que muitos destes sequer detalharam o instrumento em questão. Não obstante, os Planos Diretores podem ter estimulado a ampliação da cobertura infraestrutural nestas áreas. Em resumo, cremos que os Planos Diretores impactaram, como dito, direta ou indiretamente, a malha infraestrutural municipal.

Nesse sentido, um dos principais objetivos do presente artigo é apreender indícios de efetividade dos Planos Diretores locais no incremento da cobertura dos serviços básicos de abastecimento de água, de energia e de coleta de esgoto municipais. Em outras palavras, se há uma correlação positiva entre a existência, a recorrência e a abrangência de serviços de infraestrutura urbana.

Enfim, são suspeitas que esperamos analisar com maior profundidade ao longo do presente artigo.

\section{Metodologia}

Para a análise aqui proposta, elegemos o Estado de São Paulo e seus municípios como estudo de caso. Trata-se do Estado mais populoso e urbanizado da Federação, apresentando parte substancial de seus municípios população acima dos 20 mil habitantes ${ }^{2}$, ou seja, com uma expressiva parcela destes obrigada a elaborar Planos Diretores há, pelo menos, uma década.

A fim de dar conta de caracterizar a existência dos Planos Diretores de um considerável universo de 645 municípios, lançamos mão dos dados oriundos da Pesquisa de Informações Básicas Municipais, também conhecida como MUNIC, elaborada pelo Instituto Brasileiro de Geografia e Estatística (IBGE).

Esta pesquisa capta dados, fornecendo insumos para a investigação acerca da estrutura, da dinâmica e do funcionamento das instituições públicas municipais, ilustrando: “[...] a qualidade dos serviços públicos locais como também a capacidade dos gestores municipais em atender às populações" (IBGE, 2013), inclusive, mediante a existência (ou não) de Planos Diretores a partir do seu módulo Gestão Pública.

A MUNIC foi criada em 1999. No entanto, os dados tabulados e disponibilizados até 2003 se encontravam em parte agregados, inclusive, por unidade da Federação, ou seja, tendo-se em vista o nível de desagregação aqui proposto, o município, estes foram de pouca valia. Justamente por isso optamos por não utilizá-los. Já as pesquisas de 2006 e 2011 não apresentavam qualquer quesito afim ao assunto aqui tratado. Por este motivo também não foram tomadas em consideração.

Outro senão da pesquisa envolve a forma como a coleta foi conduzida. 0 principal informante é a própria Prefeitura por meio de seus diversos setores, diretorias, pastas etc., ou melhor, a pesquisa é feita por autodeclaração, sem a presença do entrevistador, isto é, o questionário é simplesmente enviado para ser preenchido pela Prefeitura. Embora haja todo um esforço na qualificação daquele que porventura responderá o questionário - geralmente, o gestor responsável pela área - por parte do

${ }^{2}$ Segundo dados do Censo Demográfico 2010, 243 municípios - de um conjunto de 645 - possuíam mais de 20 mil, correspondendo a $37,7 \%$ do todo (IBGE, 2010). 
IBGE, não é raro ocorrerem discrepâncias, até certo ponto significativas, entre o que é informado e a realidade de fato.

Os municípios foram recategorizados da seguinte forma: sempre possuíram Planos Diretores (20042013), Nunca possuíram Planos Diretores (2004-2013). Tal procedimento exclui do universo todos aqueles que informaram possuir Plano Diretor para, no ano seguinte, se contradizerem.

A partir deste filtro inicial, de um total de 645 municípios 339 foram, de fato, investigados: 273 nunca possuíram Planos Diretores ao longo do período (80,5\%) e 66 sempre os possuíram (19,5\%).

Posteriormente, os dados foram tabulados tanto no software Excel quanto no programa estatístico SPSS.

Por fim, cartogramas foram criados lançando-se mão da Malha Digital Municipal (MDM) do IBGE (escala: 1:2.500.000, projeção geográfica, SAD69). A versão de 2005 já dispõe dos novos municípios, criados após o Censo Demográfico de 2000. Embora, no caso do Estado de São Paulo nenhum novo município tenha sido criado no período. Tampouco novos municípios paulistas foram criados posteriormente, ou seja, o mesmo pode ser dito quanto à malha digital municipal de 2007 (CoutinhoRodrigues et al., 2011).

Com o propósito de descrever, resumidamente, as condições e as variações de cobertura de infraestrutura recorremos a um indicador sintético sobre o assunto. Este versa sobre algumas dimensões do ambiente urbano, em particular: a) abastecimento de água; b) cobertura da rede coletora de esgoto; e, por fim, c) proporção de domicílios urbanos permanentes atingidos por rede de energia elétrica (Equação 1).

$$
i \operatorname{IED}=\frac{1}{3}[\operatorname{RGA}(\%)+\operatorname{RE}(\%)+\operatorname{REI}(\%)]=\%
$$

em que $\boldsymbol{R} \boldsymbol{G A}, \boldsymbol{R} \boldsymbol{E}$ e $\boldsymbol{R} \boldsymbol{E} \boldsymbol{I}$ medem, respectivamente, a proporção de domicílios urbanos permanentes atendidos por rede geral de água, por rede de esgoto e por rede de energia elétrica.

Como dito, limitamos nossas análises à situação do domićlio. É preciso dizer que excluímos todos os domicílios particulares permanentes rurais. Cremos que dessa maneira minimizamos os vieses porventura provocados ao comparar a cobertura infraestrutural domiciliar urbana à rural, já que são de natureza complementamente distintas. Cabe esclarecer que em 2010, o Estado de São Paulo apresentava 95,9\% de grau de urbanização, isto é, praticamente a totalidade da população paulista reside em áreas urbanas, logo, praticamente todos os domicílios particulares permanentes igualmente se encontram nas áreas urbanas. Em suma, não nos parece que recortar a análise em função da situação do domićlio diminua a significância estatística ou a capacidade de generalizações das análises - ao menos quando estamos versando sobre o urbano. Nesse sentido, grande parte dos efeitos de falácia ecológica ou MAUP (Modifiable Areal Unit Problem) são minimizados, embora estes, de fato, ainda se manifestem em áreas urbanas (Dias et al., 2002). Uma solução seria utilizarmos a grade estatística do IBGE. Todavia, esse artifício geraria novos problemas de técnica a serem resolvidos; por exemplo, a compatibilização da grade ao limite urbano e ao limite dos setores censitários. Em síntese, dados os pressupostos e objetivos do presente artigo, não acreditamos que estas adversidades tenham comprometido as análises, da mesma forma que são possibilidades para aperfeiçoarmos a técnica futuramente.

Para tanto, afora o manejo da MUNIC, foram operadas também outras duas fontes secundárias de dados, quais sejam: os dados sintetizados das Informações dos Municípios Paulistas (IMP), da Fundação Sistema Estadual de Análise de Dados de São Paulo (SEADE-SP) e os microdados (do universo e da amostra) - quando necessário - dos Censos Demográficos de 2000 e 2010.

Outro obstáculo enfrentado - postos os objetivos da pesquisa - foi operacionalizar a correlação entre diferentes tipos de variáveis: uma categórica-nominal e outra discreta.

Contudo, como mencionado anteriormente, a variável nominal é composta apenas de duas categorias: a) sempre possuíram Planos Diretores; e b) nunca possuíram Planos Diretores. Soluciona-se tal impasse com a adoção da técnica ponto-bisserial. 
Particularmente, nesse caso é possível recodificar a variável dicotômica, resumindo-a ao binário 0 e 1 ( 0 para todos os municípios que nunca possuíram Planos Diretores e 1 para os que sempre os possuíram).

O coeficiente de correlação ponto-bisserial ( $\left(\widehat{\rho_{\mathrm{pb}}}\right)$ é derivado do coeficiente de correlação de Pearson e é indicado quando uma das variáveis é dicotômica e a outra é contínua e pode ser definido como (Equação 2).

$\widehat{\rho_{p b}}=\frac{(\overline{\text { iIED }}-\overline{\text { IIED }})}{S_{\text {iIED }}} \sqrt{\frac{p}{q}}$

em que $\widehat{\boldsymbol{\rho}_{\mathrm{pb}}}$ é o coeficiente de correlação ponto-bisserial; $\overline{\boldsymbol{I I E D}_{p}}$ é o índice médio do grupo cujos municípios sempre possuíram Plano Diretor; $\overline{\text { IIED }}$ é o índice médio geral dos municípios, $S_{\text {IIED }}$ é o desvio padrão amostral dos índices calculados, $p$ é a proporção de municípios que sempre tiveram Plano Diretor e $q$ é a proporção de municípios que nunca tiveram Plano Diretor.

Assim como o coeficiente de correlação de Pearson, o coeficiente de correlação ponto-bisserial assume valores no intervalo [-1,1] e mede o grau de associação linear entre as variáveis estudadas.

\section{Resultados e discussões}

\section{A limitação dos Planos Diretores diante dos passivos "herdados"/gerados}

A Figura 1 esclarece aqueles municípios ${ }^{3}$ que possuíam ou não Planos Diretores e, assim, retrata, ainda que num primeiro momento de maneira puramente visual, as porções e proporções do território paulista regulamentadas e não regulamentadas por leis municipais específicas ao longo de alguns anos da década de 2000.

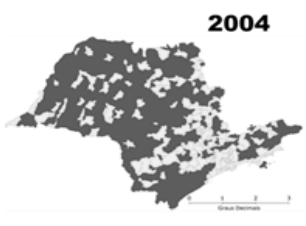

2009
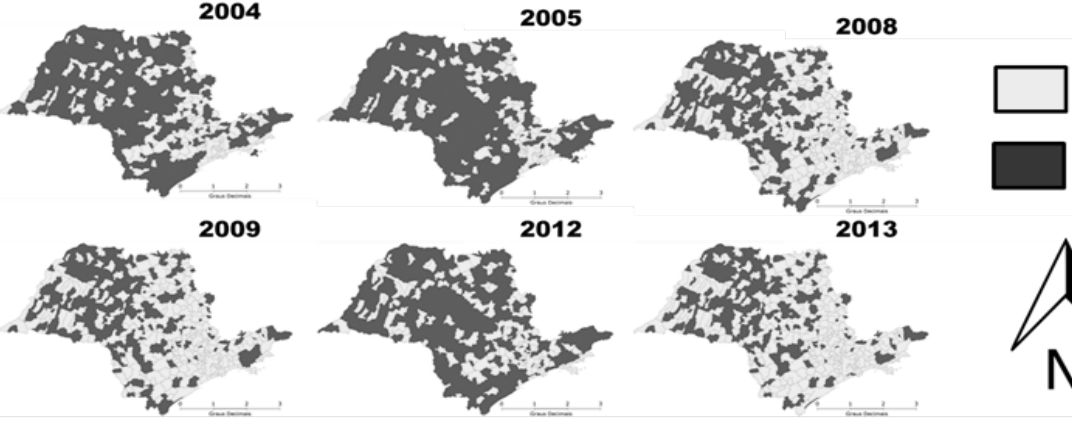

Há Plano Diretor

Não há Plano Diretor

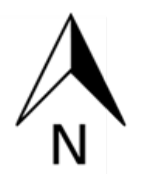

Figura 1 - Existência de Planos Diretores segundo municípios paulistas, Estado de São Paulo, 2004, 2005, 2008, 2009, 2012 e 2013. Fonte: IBGE (2004, 2005a, 2005b, 2005c, 2007a, 2008, 2009, 2012, 2013). Elaboração própria4.

Os dados uma vez recategorizados elucidam a perenidade dos Planos Diretores no Estado de São Paulo em igual intervalo temporal (Figura 2).

\footnotetext{
${ }^{3}$ De um universo de 645 municípios.

${ }^{4}$ E, variáveis: Variável A30, Variável A77, Variável A79, Variável A56, Variável A36 e Variável A34.
} 


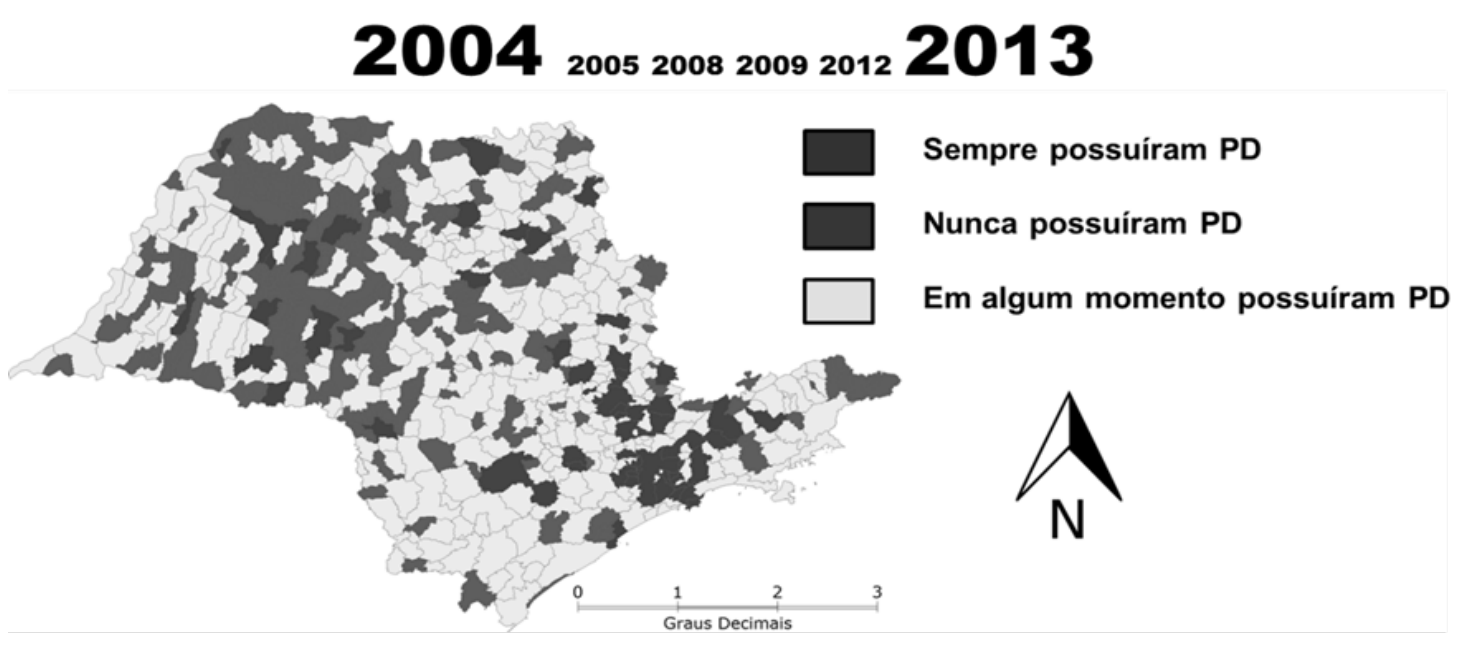

Figura 2 - Perenidade de Planos Diretores segundo municípios paulistas, Estado de São Paulo, 2004, 2005, 2008, 2009, 2012 e 2013. Fonte: IBGE (2004, 2005a, 2005b, 2007a, 2007b, 2008, 2009, 2012, 2013). Elaboração própria.

Talvez, uma das primeiras maneiras de se esclarecer a relevância dos Planos Diretores no ambiente físico-material das cidades seja analisando sua distribuição (Gráfico 1), segundo o Índice de Infraestrutura do Entorno Domiciliar (iIED).
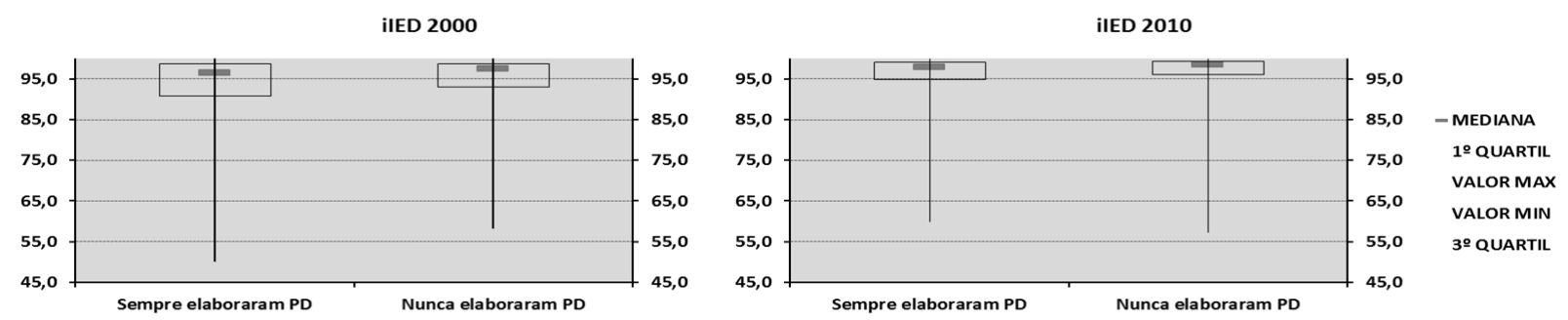

Gráfico 1. Distribuição do Índice de Infraestrutura Domiciliar segundo existência de Planos Diretores Municipais, Domicílios Particulares Permanentes Urbanos, Estado de São Paulo, 2000, 2010. Fonte: IBGE (2000, 2004, 2005b, 2008, 2009, 2010, 2012, 2013). Elaboração própria.

Podemos notar que a distribuição do índice, em 2000, de acordo com as categorias de municípios, é relativamente semelhante.

É também possível depreender - ao menos no caso paulista - que a cobertura de serviços de água, esgoto, lixo e energia é territorialmente bem disseminada e praticamente universalizada, atingindo boa parte dos domicílios particulares permanentes urbanos destes municípios.

Parece importante comentar que os altos valores do índice atingidos previamente ao Estatuto das Cidades podem inviabilizar a correlação entre as variáveis operativas, haja vista que já em 2000 aproximadamente 75\% dos casos (municípios) apresentam índices de abrangência superiores a 90\%. Em síntese, uma rede decerto capilarizada. Assim, futuramente seria interessante compararmos os dados paulistas às condições infraestruturais de outros Estados, por exemplo, aos dados de Minas Gerais. A comparação seria um artifício que possibilitaria a avaliação da relevância da variável independente: existência (ou não) de Planos Diretores.

Embora os grupos guardem considerável paridade e, da mesma forma, apresentem vasta abrangência infraestrutural, os dados demonstram que municípios que sempre elaboraram Planos Diretores apresentavam piores índices em comparação aos municípios que nunca os arquitetaram, diferentemente do que supúnhmos inicialmente. Nesse sentido, acreditamos que a menor cobertura infraestrutural característica dos municípios que sempre arquitetaram Planos Diretores é fruto da sua própria condição de áreas de concentração populacional (populações maiores de 20 mil habitantes), do seu poder de atração populacional (antigas áreas de destino de fluxos imigratórios), de suas elevadas 
taxas de crescimento populacional pregressas etc., desdobrando-se dinâmicas urbanas efervescentes. Em síntese, cremos que os Planos Diretores se sobrepõem às antigas e novas razões socioeconômicas, que persistem reproduzindo nestes municípios as situações de desigualdade tanto socioeconômicas quanto infraestruturais, ou seja, territoriais (Sagalés \& Lorda, 2006). Imaginamos que os problemas eminentemente urbanos (loteamentos clandestinos, irregulares, ocupações, crescimento especulativo e seus reflexos infraestruturais: dificuldade de abastecimento de água, coleta de esgoto e energia elétrica) foram mais seriamente sentidos e acumulados. Em realidade, não é casual que estes municípios tenham sempre elaborado Planos Diretores. De um lado, são obrigados por lei a tanto. De outro, este é o esforço - a manifestação legal e social - de se equalizar estas mesmas desigualdades. Não é fortuito, portanto, que os Planos Diretores venham associados às mais baixas coberturas infraestruturais, cuja média, por exemplo, é de 92,5\%; enquanto que a média - para o mesmo ano (2000) - dos municípios que nunca elaboraram Planos Diretores é de 94,0\% (Sivam, 2002).

Em 2010, a distribuição foi similar. Em realidade, os índices foram incrementados ainda mais, independentemente da condição legal do município.

Em resumo, já a partir do Gráfico 1 é possível afirmar que não há uma correlação positiva entre ambos os domínios. Logo, que os Planos Diretores não estão sendo determinantes para o avanço da cobertura dos serviços de infraestrutura urbana, uma vez que a distribuição da variável dependente (iIED) não se altera, substancialmente, conforme a existência de Planos Diretores. Em outras palavras, parece haver uma melhora generalizada nos indicadores de infraestrutura, independentemente da existência de Planos Diretores. 0 iIED médio em 2000, 93,7\%, passa, em 2010, para 95,9\%.

Desse modo, a correlação ponto-bisserial foi igual a $\widehat{\rho_{p b}}(2000)=-0,07$, indicando que não existe associação linear significativa entre a abrangência infraestrutural e o fato de ter ou não Plano Diretor.

Novamente, a correlação ponto-bisserial - $\widehat{\rho_{p b}}(2010)=-0,06$ - não foi significativa, indicando que não existe associação linear entre ambos os domínios. Logo, os Planos Diretores não estão sendo determinantes para o avanço da cobertura dos serviços de infraestrutura urbana.

No entanto, há uma singularidade a partir de 2010.

0 iIED médio dos municípios que sempre elaboraram Planos Diretores atinge 95,1\% (este era de 92,5\%, representando uma variação de 2,6\% para o período). Já para o grupo de municípios que nunca arquitetaram Planos Diretores, a média passa a ser 96,1\% (este era de 94,0\%, com uma variação de 2,1\%) (Tabela 1).

Tabela 1 - Índice de Infraestrutura do Entorno Domiciliar segundo existência de Planos Diretores Municipais, Domicílios Particulares Permanentes Urbanos, Estado de São Paulo, 2000

\begin{tabular}{|c|c|c|c|c|c|c|c|c|c|}
\hline & \multicolumn{3}{|c|}{ Sempre elaboraram PD* } & \multicolumn{3}{|c|}{ Nunca elaboraram PD* } & \multicolumn{3}{|c|}{ Passaram a possuir } \\
\hline & $\begin{array}{c}\text { IIED } \\
2000 \\
(\%)\end{array}$ & $\begin{array}{c}\text { ilED } \\
2010(\%)\end{array}$ & $\begin{array}{c}\text { Variaçã } \\
\text { o } 2000- \\
2010(\%)\end{array}$ & $\begin{array}{c}\text { ilED } \\
2000(\%)\end{array}$ & $\begin{array}{c}\text { ilED } \\
2010(\%)\end{array}$ & $\begin{array}{c}\text { Variaçã } \\
\text { o 2000- } \\
2010(\%)\end{array}$ & $\begin{array}{c}\text { ilED } \\
2000(\%)\end{array}$ & $\begin{array}{c}\text { ilED } \\
2010(\%)\end{array}$ & $\begin{array}{c}\text { Variaçã } \\
02000- \\
2010(\%)\end{array}$ \\
\hline MÉDIA & 92,5 & 95,1 & 2,6 & 94,0 & 96,1 & 2,1 & 93,4 & 95,6 & 2,2 \\
\hline MODA & 99,3 & $\# N / D$ & $\# N / D$ & 98,7 & 99,2 & 0,5 & 97,0 & 97,9 & 0,9 \\
\hline MEDIANA & 96,6 & 97,9 & 1,3 & 97,4 & 98,5 & 1,0 & 97,0 & 98,2 & 1,2 \\
\hline 1Q QUARTIL & 90,7 & 94,9 & 4,2 & 93,1 & 96,2 & 3,1 & 91,6 & 94,7 & 3,1 \\
\hline $\begin{array}{l}\text { VALOR } \\
\text { MÁX }\end{array}$ & 100,0 & 99,9 & 0,0 & 100,0 & 100,0 & 0,0 & 100,0 & 100,0 & 0,0 \\
\hline $\begin{array}{c}\text { VALOR } \\
\text { MÍN }\end{array}$ & 50,2 & 59,8 & 9,6 & 58,3 & 57,2 & $-1,1$ & 58,0 & 62,8 & 4,7 \\
\hline $3^{\circ}$ QUARTIL & 98,8 & 99,2 & 0,4 & 98,7 & 99,3 & 0,6 & 98,8 & 99,2 & 0,3 \\
\hline
\end{tabular}

*PD = Planos Diretores. Fonte: IBGE (2000, 2004, 2005b, 2008, 2009, 2010, 2012, 2013). Elaboração própria.

A novidade ocorre entre os municípios com piores atributos infraestruturais. Enquanto, em 2000, o valor mínimo de iIED registrado pelos municípios que sempre elaboraram Planos Diretores era de $50,2 \%$, e de 58,3\% dos municípios que não desenvolveram seus Planos (representando uma diferença 
de 8,1\%), em 2010, estes valores passam a ser de, respectivamente: 59,8\% e 57,2\% (uma diferença em favor dos municípios com Planos Diretores de 2,7\%), ou seja, os dados se invertem.

0 interessante é atentar para o fato de que ao longo da década há uma melhora perceptível sobretudo entre os piores casos dos municípios (último quartil) que tinham Planos Diretores, em detrimento dos que não os possuíam.

A variação foi positiva para os primeiros $(+9,6 \%)$ e negativa para a segunda categoria de municípios: $-1,1 \%$, demonstrando ligeira piora nos indicadores de infraestrutura, justamente entre os municípios sem Planos Diretores.

Em outras palavras, a velocidade e a intensidade da melhora foram sentidas, sobretudo, entre aqueles municípios que apresentavam defasagens infraestruturais, mas que também sempre arquitetaram Planos Diretores ao longo da década. Pode ser este um indício que relativiza a baixa correlação geral entre Planos Diretores e índices de cobertura infraestrutural. É dizer, se no geral a correlação é nula, esta é mais manifesta em alguns grupos de municípios, isto é, naqueles com baixas coberturas infraestruturais, ou seja, os Planos Diretores são fundamentais nos municípios mais carentes, ao menos do ponto de vista infraestrutural. Assim, tal assertiva nos leva a pensar que estes também sejam imprescindíveis em outros domínios da vida urbana (Panagopoulos et al., 2015).

Embora não haja diferenças estatisticamente significativas entre o primeiro quartil e demais quartis dos municípios que sempre elaboraram Planos Diretores, os dados da Tabela 2 nos ajudam a entender os obstáculos herdados pelos municípios mais carentes (1ํquartil). Um exemplo é a taxa geométrica de crescimento populacional ao ano (TGCA) entre 1991 e 2000. Esta foi de 2,4\% a.a. nos municípios que sempre elaboraram Planos Diretores, enquanto não ultrapassou $1 \%$ a.a. entre os municípios que nunca os desenvolveram. Esta diferença aponta para o já afirmado, municípios que sempre elaboraram Planos Diretores enfrentaram dificuldades distintas daqueles que nunca os elaboraram, como, por exemplo, se viram às voltas com um rápido processo de crescimento demográfico. Decerto, não pretendemos responsabilizar a população pelas carências infraestruturais, ao contrário, apenas ponderar que os municípios estão expostos a processos e fenômenos distintos, produzindo coberturas infraestruturais igualmente diferentes.

Tabela 2 - Indicadores médios segundo existência de Planos Diretores Municipais, Domicílios Particulares Permanentes Urbanos, Estado de São Paulo, 2000, 2010

\begin{tabular}{cccc}
\hline & Total de Municípios SP & $\begin{array}{c}\text { Sempre Elaboraram } \\
\text { PD* }\end{array}$ & $\begin{array}{c}\text { Nunca elaboraram } \\
\text { PD* }\end{array}$ \\
\hline MÉDIA TGCA1991-2000 & 1,6 & 2,4 & 1,0 \\
MÉDIA TGCA 2000-2010 & 1,0 & 1,3 & 0,9 \\
MÉDIA VARIIED 2000-2010 & 2,2 & 2,6 & 2,1 \\
MÉDIA IIED 2000 & 93,6 & 92,5 & 94,0 \\
MÉDIA IIED 2010 & 95,8 & 95,1 & 96,1 \\
MÉDIA TGCA 1991-2000 10 QUARTIL & 1,6 & 2,4 & 1,0 \\
MÉDIA TGCA 2000-2010 10 QUARTIL & 1,0 & 1,3 & 0,8 \\
MÉDIA IIED 2000 10 QUARTIL & 93,5 & 92,1 & 93,9 \\
MÉDIA IIED 2010 10 QUARTIL & 95,7 & 94,8 & 96,1 \\
MÉDIA VARIIED 2000-2010 10 QUARTIL & 0,9 & 2,7 & 2,2 \\
\hline
\end{tabular}

*PD = Planos Diretores. Fonte: IBGE (2000, 2004, 2005b, 2008, 2009, 2010, 2012, 2013). Elaboração própria.

Enfim, o que os dados parecem demonstrar são tênues carências infraestruturais concentradas, sobretudo, nos municípios que sempre elaboraram Planos Diretores. As causas parecem evidentes.

Como dito, supomos que o índice poderia estar correlacionado com fenômenos, processos e dinâmicas tipicamente urbanas mais ou menos vigorosas. É dizer, quão acelerado - e talvez desenfreado - seja o crescimento da cidade, mais deficitárias seriam as redes e os serviços de infraestrutura, uma vez que sua velocidade de implementação estaria, possivelmente, aquém do crescimento demográfico/urbano. De qualquer maneira, nos parece que os Planos Diretores deveriam ser mais incisivos de modo a assegurar maior eficácia e, assim, romper com o ciclo de reprodução das desigualdades socioespaciais (Valenzuela, 2005). 
Novamente, os dados não permitem afirmações absolutas. Não é possível evidenciar - para o conjunto de municípios paulistas - uma forte correlação entre variação do grau de urbanização ou taxas geométricas de crescimento anual da população (1991-2000 e 2000-2010) e universalidade dos serviços de infraestrutura urbana. Conquanto notamos uma tendência à correlação negativa, isto é, como inferido previamente, de acordo com a velocidade e, mormente, vigor do crescimento do grau de urbanização e da taxa geométrica de crescimento anual da população parece haver, pari passu, uma piora dos indicadores de infraestrutura básica (Tabela 3).

Tabela 3 - Valores de correlação entre Grau de Urbanização, Taxa Geométrica de Crescimento Anual e Índices de Infraestrutura do Entorno Domiciliar segundo existência de Planos Diretores Municipais, Domicílios Particulares Permanentes Urbanos, Estado de São Paulo, 1991, 2010

\begin{tabular}{|c|c|c|c|}
\hline Correlação de Pearson & Total de Municípios SP & $\begin{array}{c}\text { Sempre Elaboraram } \\
\text { PD* }\end{array}$ & $\begin{array}{c}\text { Nunca elaboraram } \\
\text { PD* } \\
\end{array}$ \\
\hline $\begin{array}{l}\text { Grau de Urbanização e Variação ilED } \\
\text { TGCA912000 e ilED2000 } \\
\text { TGCA200010 e ilED2010 }\end{array}$ & $\begin{array}{l}-0,07 \\
-0,09 \\
-0,02\end{array}$ & $\begin{array}{l}-0,11 \\
-0,15 \\
-0,08\end{array}$ & $\begin{array}{l}-0,08 \\
0,06 \\
0,05\end{array}$ \\
\hline $\begin{array}{c}\text { Grau de Urbanização e Variação ilED } \\
\text { ( } 1^{\circ} \text { Quartil) }\end{array}$ & $-0,07$ & $-0,11$ & $-0,09$ \\
\hline $\begin{array}{l}\text { TGCA912000 e ilED2000 ( } 1^{\circ} \text { Quartil) } \\
\text { TGCA200010 e ilED2010 ( } 1^{\circ} \text { Quartil) }\end{array}$ & $\begin{array}{l}-0,10 \\
-0,02\end{array}$ & $\begin{array}{l}-0,16 \\
-0,10\end{array}$ & $\begin{array}{l}0,06 \\
0,05\end{array}$ \\
\hline
\end{tabular}

*PD = Planos Diretores. Fonte: IBGE (2000, 2004, 2005b, 2008, 2009, 2010, 2012, 2013). Elaboração própria.

Como dito, não é possível falar em correlação, contudo há indícios de que o Índice de Infraestrutura do Entorno Domiciliar seja inversamente afetado pelas altas taxas de crescimento anual da população apresentadas ao longo do período 1991-2000, ecos de taxas ainda mais intensas experienciadas nas décadas precedentes, sobretudo a partir dos anos 1950, período caracterizado por industrialização e urbanização acelerada, concentração populacional, altas taxas de fecundidade e migração de longa distância. Em resumo, dinâmica urbana pujante. Recortes temporais mais abrangentes poderiam elucidar o que foi ventilado.

O mapeamento do quartil mais deficitário em infraestruturas dentre os municípios que sempre elaboraram Planos Diretores parece confirmar a inferência de que se tratam de municípios que muito cresceram em décadas passadas (Figura 3).

\section{0}

\section{0}

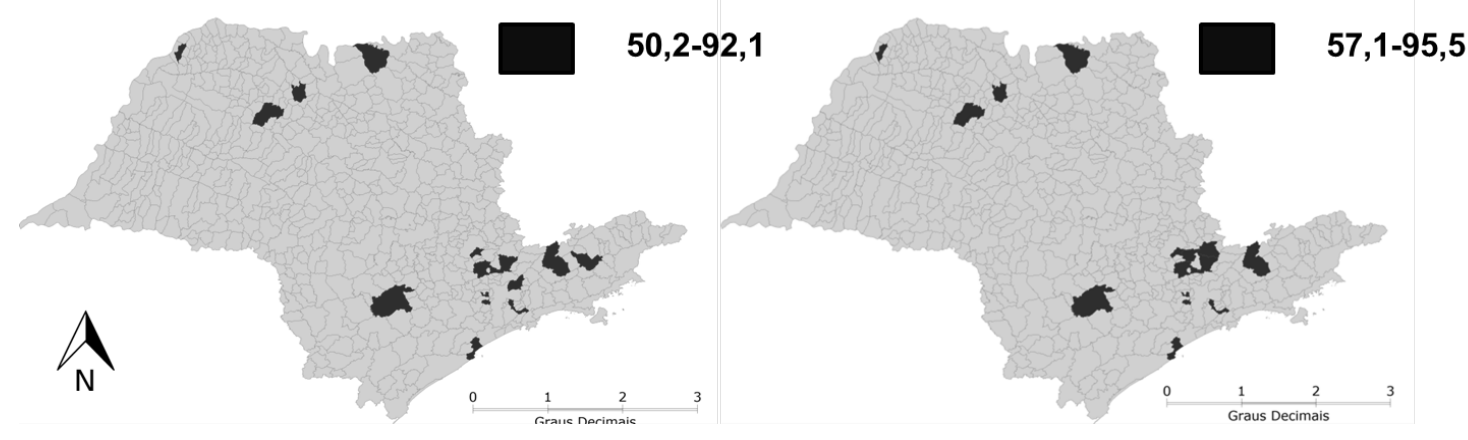

Figura 3 - Municípios do $1^{\circ}$ quartil do Índice de Infraestrutura do Entorno Domiciliar segundo a existência de Planos Diretores (sempre elaboraram PD), Domicílios Particulares Permanentes Urbanos, Estado de São Paulo,

2000, 2010. Fonte: IBGE (2000, 2004, 2005b, 2008, 2009, 2010, 2012, 2013). Elaboração própria.

Apresentam-se como municípios próximos a grandes centros, cidades médias emergentes (Jundiaí, São José do Rio Preto, São José dos Campos e Sorocaba) ou integrantes de regiões metropolitanas (RM de São Paulo, Campinas e Santos), em resumo, municípios sobre a influência desses centros. Muitos destes municípios se configuram como vetores de crescimento periférico destas sedes regionais. 


\section{Conclusões}

O resultado encontrado não é de modo algum frustrante. Afinal, a não correlação entre ambos os domínios está igualmente carregada de significados.

Os dados demonstram que Planos Diretores - símbolos de ordenamento territorial e regulamentação local - não estão sendo decisivos na melhoria da cobertura de serviços básicos de infraestrutura, ao menos para o recorte temporal e territorial em questão.

Conquanto, é deveras importante alertar. 0 presente artigo não pretende transmitir a ideia de que os Planos Diretores são irrelevantes. Ao contrário, desejamos demonstrar que Planos Diretores precisam ser mais agudos, mais arrojados e sagazes, mais articulados a objetivos, inclusive, regionais. Estes necessitam cobrar com maior vigor incorporadores, concessionárias particulares ou públicas, agências de fiscalização e secretarias estaduais e nacionais com o propósito de coordenar e disciplinar ações. Necessitam estar alinhavados com a realidade de seus vizinhos imediatos (Villaça, 2010). Haja vista a falência do planejamento regional estatal parece que os Consórcios Intermunicipais se mostram como uma solução possível à desarticulação territorial.

Enfim, a atuação deve ser multiescalar, multisetorial e vertical, com especial atenção aos municípios lindeiros às Regiões Metropolitanas paulistas: Campinas, São Paulo e Baixada Santista. Não parece casual que áreas como Sorocaba-Itapetininga, Jundiaí, São José do Rio Preto e São José dos Campos sejam algumas que apresentem os piores índices de infraestrutura, embora possuam Planos Diretores. Ao menos medidas estão sendo tomadas para se harmonizar esta desarticulação com a criação de mais uma divisão administrativa intraestadual: os Aglomerados Urbanos.

Embora a cobertura infraestrutural paulista se aproxime da totalidade, tampouco é completa. E por que se ater a isso? Porque pode ser este mais um vestígio de que Planos devam ser mais peremptórios. Ainda que haja uma enormidade de configurações e padrões morfológicos e tipológicos de assentamentos urbanos, tais como chácaras de recreio (em áreas urbanas), por exemplo, que, em geral, não se inserem na rede de abastecimento de água ou coleta de esgoto, acreditamos que boa parte dos não assistidos por serviços infraestruturais básicos residam em áreas realmente mais carentes de recursos: assentamentos precários, aglomerados subnormais, ocupações e favelas. Planos Diretores devem lutar para que estas áreas sejam capilarizadas por infraestruturas básicas, buscando assim reduzir desigualdades socioeconômicas através da disseminação de um mínimo de serviços básicos.

Novos estudos comparativos podem jogar luz para a associação entre Planos e infraestrutura, como, por exemplo, comparando Estados como Minas Gerais e São Paulo, uma vez que os altos índices de cobertura paulista podem enviesar a análise. Presumimos que os indicadores de Minas Gerais sejam distintos e mais próximos à média brasileira, dando novos indícios de sua relevância ou dos caminhos a seguir. Seria interessante esmiuçar o que de fato está ocorrendo nestas regiões sob a égide dos grandes centros urbanos paulistas. Além disso, uma análise multifatorial na qual os Planos Diretores seriam um destes componentes poderia ser útil.

\section{Agradecimentos}

Agradecimentos à FAPEMIG pelo apoio financeiro e institucional na elaboração da presente investigação.

\section{Referências}

Arretche, M. T. S. (1999). Políticas sociais no Brasil: descentralização em um Estado federativo. Revista Brasileira de Ciências Sociais, 14(40), 111-141. http://dx.doi.org/10.1590/S0102-69091999000200009.

Barton, J. R., Jordán, R., León, S. M., \& Solis, M. (2007). ¿Cuán sustentable es la Región Metropolitana de Santiago? Metodologías de evaluación de la sustentabilidad (Colección Documentos de Proyectos). Santiago: Comisión Económica para América Latina y el Caribe. 
Bernardy, R. J. (2013). 0 planejamento urbano de pequenos municípios com base no plano diretor. Desenvolvimento em Questão, 11(22), 4-34. http://dx.doi.org/10.21527/2237-6453.2013.22.4-34.

Boscá, J. E., Escribá, J., \& Murgui, M. J. (2011). La efectividad de la inversión en infraestructuras públicas: una panorámica para la economía española y sus regiones. Investigaciones Regionales, 20, 195-217.

Braga, R. (1993). Aspectos da ordenação territorial nas leis orgânicas municipais do Estado de São Paulo (Dissertação de mestrado). Universidade de São Paulo, São Paulo.

Braga, R. (1995). Plano diretor municipal: três questões para discussão (Vol. 1, No. 1, pp. 15-20). Presidente Prudente: Departamento de Planejamento, UNESP.

Brandão, C. (2007). Território \& desenvolvimento: as múltiplas escalas entre o local e o global. Campinas: Editora da Unicamp.

Brasil. (1988, 5 de outubro). Constituição da República Federativa do Brasil de 1988. Brasília: Diário Oficial da União.

Brasil. (2001, 11 de julho). Lei no 10.257, de 10 de julho de 2001. Regulamenta os arts. 182 e 183 da Constituição Federal, estabelece diretrizes gerais da política urbana e dá outras providências. Brasília: Diário Oficial da União. Recuperado em 23 de outubro de 2015, de https://www.planalto.gov.br/ccivil_03/Leis/LEIS_2001/L10257.htm

Caiado, A. S. C. (1995). Dinâmica socioespacial e a rede urbana paulista. São Paulo em Perspectiva, 9(3), 46-53.

Correa, G., \& Rozas, P. (2006). Desarrollo urbano e inversiones en infraestructura: elementos para la toma de decisiones (Serie DRNI, No. 108). Santiago: CEPAL.

Coutinho-Rodrigues, J., Simão, A., \& Antunes, C. H. (2011). A GIS-based multicriteria spatial decision support system for planning urban infrastructures. Decision Support Systems, 51(3), 720-726.

http://dx.doi.org/10.1016/j.dss.2011.02.010.

Cymbalista, R., \& Santoro, P. F. (2009). Planos diretores: processos e aprendizados. São Paulo: Instituto Pólis.

Dias, T. D. L., Oliveira, M. P. G., Câmara, G., \& Carvalho, M. S. (2002). Problemas de escala e a relação área-indivíduo em análise espacial de dados censitários. Informática Pública, 4(2), 89-104.

Fausto, A. \& Rábago, J. (2014). ¿Vacíos urbanos o vacíos de poder metropolitano? Boletín CF+ S, (21), 33-39.

Figueroa, O. (2004). Infraestructura, servicios públicos y expansión urbana en Santiago. In C. Mattos, M. E. Ducci, A. Rodriguez, \& G. Yanez (Eds.), Santiago en la globalización: una nueva ciudad. Santiago: SUR Corporacion.

Instituto Brasileiro de Geografia e Estatística - IBGE. (2000). Censo demográfico 2000. Rio de Janeiro: IBGE.

Instituto Brasileiro de Geografia e Estatística - IBGE. (2004). Perfil dos municípios brasileiros: gestão pública 2004. Rio de Janeiro: IBGE.

Instituto Brasileiro de Geografia e Estatística - IBGE. (2005a). Área territorial Oficial. Base Cartográfica. Malha Municipal Digital - 2005. Projeção Geográfica (LatLong. Datum:SAD69). Escala 1:2.500.000. Rio de Janeiro: IBGE. Recuperado em 20 de agosto de 2014, de ftp://geoftp.ibge.gov.br/malhas_digitais/municip_io2005/escala_2500mil/proj_geografica/arcview_shp/uf/sp/ Instituto Brasileiro de Geografia e Estatística - IBGE. (2005b). Perfil dos municípios brasileiros: gestão pública 2005. Rio de Janeiro: IBGE.

Instituto Brasileiro de Geografia e Estatística - IBGE. (2005c). Malhas digitais municipais. Rio de Janeiro: IBGE.

Instituto Brasileiro de Geografia e Estatística - IBGE. (2007a). Área territorial Oficial. Base Cartográfica. Malha Municipal Digital. Projeção Geográfica (LatLong. Datum:SAD69). Escala 1:2.500.000. Rio de Janeiro: IBGE. Recuperado em 20 de agosto de 2015, de ftp://geoftp.ibge.gov.br/malhas_digitais/municipio_2007/escala_2500mil/proj_geografica_sad69/uf/sp/

Instituto Brasileiro de Geografia e Estatística - IBGE. (2007b). Malhas digitais municipais. Rio de Janeiro: IBGE. Recuperado em 20 de agosto de 20154 de ftp://geoftp.ibge.gov.br/malhas_digitais/municipio_2007/escala_2500mil/proj_geografica_sad69/uf/sp Instituto Brasileiro de Geografia e Estatística - IBGE. (2008). Perfil dos municípios brasileiros: gestão pública 2008. Rio de Janeiro: IBGE. 
Instituto Brasileiro de Geografia e Estatística - IBGE. (2009). Perfil dos municípios brasileiros: gestão pública 2009. Rio de Janeiro: IBGE.

Instituto Brasileiro de Geografia e Estatística - IBGE. (2010). Censo demográfico 2010. Rio de Janeiro: IBGE.

Instituto Brasileiro de Geografia e Estatística - IBGE. (2012). Perfil dos municípios brasileiros: gestão pública 2012. Rio de Janeiro: IBGE.

Instituto Brasileiro de Geografia e Estatística - IBGE. (2013). Perfil dos municípios brasileiros: gestão pública 2013. Rio de Janeiro: IBGE.

Kowarick, L. (1980). A espoliação urbana. Rio de Janeiro: Paz e Terra.

Lacerda, N., Marinho, G., Bahia, C., Queiroz, P., \& Pecchio, R. (2011). Planos diretores municipais: aspectos legais e conceituais. Revista Brasileira de Estudos Urbanos e Regionais, 7(1), 55-72.

Maricato, E. (2003). Metrópole, legislação e desigualdade. Estudos Avançados, 17(48), 151-166. http://dx.doi.org/10.1590/S0103-40142003000200013.

Maricato, E. (2009). Por um novo enfoque teórico na pesquisa sobre habitação. Cadernos Metrópole, (21), 33-52.

Ojima, R., \& Hogan, D. J. (2009). Mobility, urban sprawl and environmental risks in Brazilian urban agglomerations: challenges for urban sustainability. Urban population-environment dynamics in the developing world: case studies and lessons learned. In A. Sherbinin, A. Rahman, A. F. Barbieri, J. C. Fotso, \& Y. Zhu (Eds.), Urban population and environment dynamics in the developing world: case studies and lessons learned (pp. 281-316.). Paris: CICRED.

Oliveira, F. L. (2013). Os novos planos diretores municipais brasileiros: uma avaliação preliminar. In Anais do XIV Encontros Nacionais da ANPUR. Rio de Janeiro: ANPUR.

Panagopoulos, T.; Duque, J. A. G. \& Dan, M. B. (2015). Urban planning with respect to environmental quality and human well-being. Environmental Pollution, 208(A), 137-144.

Penna, N. A., \& Ferreira, I. B. (2014). Desigualdades socioespaciais e áreas de vulnerabilidade nas cidades. Mercator, 13(3), 25-36. http://dx.doi.org/10.4215/RM2014.1303.0002.

Sagalés, O. R. \& Lorda, H. S. (2006). Efectos desbordamiento de la inversión en infraestructuras en las regiones españolas. Investigaciones Regionales, (8), 143-161.

Santos, M. P., da Cunha, M. S., \& de Brito Gadelha, S. R. (2017). Distribuição de renda e desenvolvimento econômico: análise da hipótese de Kuznets para os estados brasileiros no período 1992-2010. Revista Brasileira de Estudos Regionais e Urbanos, 11(2), 251-271.

Sivam, A. (2002). Constraints affecting the efficiency of the urban residential land market in developing countries: a case study of India. Habitat International, 26(4), 523-537. http://dx.doi.org/10.1016/S0197-3975(02)00025-5.

Urbano, P. M. (2005). El papel de las infraestructuras públicas en el desarrollo regional. Nóesis. Revista de Ciencias Sociales y Humanidades, 15(17), 45-67.

Valenzuela, L. (2005). Periferia e infraestructura en el paradero 14. ARQ, 60(60), 62-64. http://dx.doi.org/10.4067/S0717-69962005006000011.

Villaça, F. (2005). As ilusões do Plano Diretor. São Paulo: USP. Recuperado em 20 de outubro 2015, de http://www.usp.br/fau/fau/galeria/paginas/index.html

Villaça, F. (2010). Dilemas do plano diretor. In Fundação Prefeito Faria Lima. O município no século XXI: cenários e perspectivas. São Paulo: CEPAM.

\section{Editor: Rodrigo Firmino}

Recebido: Maio 16, 2018

Aprovado: Dez. 26, 2018 